\title{
Evolution of the determinants of chronic liver disease in Quebec
}

\author{
A. J. Sanabria, MSc (1, 2); R. Dion, MD (3); E. Lúcar, BSc (1, 4); J. C. Soto, MD (1)
}

This article has been peer reviewed.

\begin{abstract}
Introduction: Chronic liver diseases (CLDs) are a worldwide problem. Morbidity and mortality due to CLDs could be avoided or reduced by targeting the main risk factors, including obesity and alcohol use.
\end{abstract}

Methods: To describe the evolution of the key determinants of CLDs in Quebec, we studied the trends in obesity, alcohol use, viral hepatitis B and C, CLD mortality and hospitalization rates, and the liver cancer incidence rate between January 1, 1981, and December 31, 2009.

Results: We observed an increase in the obesity indicators among young men and in alcohol use among adolescent girls and middle-aged women. The overall hepatitis B and $\mathrm{C}$ incidence and CLD mortality rates are falling. However, liver cancer and mortality rates, especially among men and the elderly, are on the rise.

Conclusion: These results highlight the importance of targeted public health interventions and of maintaining or improving access to care for CLDs.

Keywords: liver disease, epidemiology, chronic disease, risk factors, chronic liver disease

\section{Introduction}

Chronic liver diseases (CLDs) have different characteristics in terms of risk factors, incubation, latency, induction and the final state of the disease process. The most common CLDs are associated with chronic viral hepatitis, alcohol use and obesity; the least common are liver cancer and those due to certain genetic, autoimmune and vascular conditions or to drug toxicity. ${ }^{1}$

CLDs are responsible for over $80 \%$ of primary liver cancers, of which hepatocellular carcinoma (HCC) is the most frequent. Chronic liver inflammation and liver tissue fibrosis provide the ideal conditions for the development of HCC. Thus, patients with HCC usually have a history of chronic viral hepatitis B (HBV) or hepatitis C (HCV), alcoholic liver disease (ALD) or non-alcoholic steatohepatitis. ${ }^{2,3}$ Alone or in combination, these diseases increase the risk of HCC. ${ }^{4-8}$

CLDs are a major public health problem worldwide. In England, they are the fifth leading cause of death; ${ }^{9}$ in the United States, they have been among the fifteen leading causes of death in the past decade, ${ }^{10-13}$ with an estimated adjusted mortality rate of 10.3 per 100000 inhabitants in 2010. ${ }^{13}$ In Canada, 2748 deaths were attributed to CLDs and liver cirrhosis (eleventh leading cause of death) in 2008, of which 1809 (66\%) were among men. ${ }^{14}$

Morbidity and mortality from CLDs could be avoided or reduced by targeting the main risk factors, including obesity and alcohol use. ${ }^{6-8}$ In addition, some compli- cations can be avoided through vaccination against hepatitis A (HAV) and HBV and diagnosis and early treatment of chronic hepatitis caused by HCV. $7,15,16$

To determine the CLD situation in Quebec, we studied their evolution and that of their main determinants. We targeted conditions for which prevention plays an important role.

\section{Methods}

Our ecological observational study looked at the period between 1 January, 1981, and 31 December, 2009. The data for the selected health indicators came from the Infocentre de santé publique (Infocentre) of the Institut national de santé publique du Québec (INSPQ), except for those on HBV- and HCV-associated morbidity, which came from Quebec's registry of notifiable diseases (RND). The Infocentre is a secure access portal to health data from various sources. ${ }^{17}$

The indicators for the selected CLD determinants were from Statistics Canada's Canadian Community Health Surveys (CCHSs) for 2000/2001, 2003/2005 and 2007/2008. ${ }^{18}$ The CCHS surveys Canadians aged 12 years and older living in private households (but excludes residents of reserves and Aboriginal settlements, Canadian Armed Forces bases, institutions and some remote areas), and are representative of Quebec's public health regions. ${ }^{18}$

The cases of HBV and HCV reported to the Quebec's RND covered the period from 1 January, 1990, to 31 December, 2009. For $\mathrm{HBV}$, we looked at acute and chronic cases and those for which the status was

\section{Author references:}

1. Direction des risques biologiques et de la santé au travail, Institut national de santé publique du Québec (INSPQ), Montréal, Quebec, Canada

2. Bellvitge University Hospital, Barcelona, Spain

3. Laboratoire de santé publique du Québec, INSPQ, Sainte-Anne-de-Bellevue, Quebec, Canada

4. McGill University, Montréal, Quebec, Canada

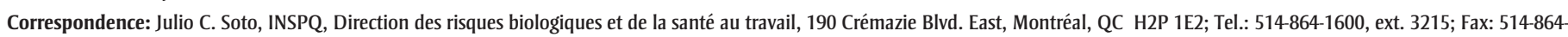
7646; Email: julio.soto@inspq.qc.ca 
unspecified. For HCV, we looked at all categories combined. These cases are recorded and classified by Quebec's regional public health departments on the basis of the nosological definitions of the ministère de la Santé et des Services sociaux (MSSS). ${ }^{19}$ These definitions are similar to those of the Public Health Agency of Canada (PHAC). ${ }^{20}$ Annual incidence rates per 100000 population were calculated for acute HBV infections, using as denominators the estimates and projections of the Institut de la statistique du Québec (ISQ). These were made on the basis of the data from the Statistics Canada censuses and published by MSSS. ${ }^{21}$ The HBV and HCV data were analyzed using the software EpiData Analysis version 2.2.1.171.22

The following health indicators were examined for association with the determinants of CLD: the proportion of the population that was overweight (body mass index [BMI] $25.0-29.9 \mathrm{~kg} / \mathrm{m}^{2}$ ) or obese (BMI $\left.\geq 30 \mathrm{~kg} / \mathrm{m}^{2}\right)^{23}$ from 2000 to 2008; the proportion of the population that used alcohol occasionally or daily over the previous twelve months from 2000 to 2008; the proportion of the population that had 14 or more alcoholic drinks over a seven-day period from 2000 to 2005; and the proportion of the population that reported heavy alcohol use (five alcoholic drinks on one occasion, i.e. one after another or in a short period of time) 12 or more times per year ${ }^{18}$ from 2000 to 2008 .

The data sources for the CLD indicators were the MSSS tumour file, the RND, and the system for maintenance and use of data for the study of hospital patients (MED-ÉCHO). ICD-9* codes were used to identify CLDs (571) and liver cancer (115) up to the year 1999, and ICD-10 ${ }^{\dagger}$ codes were used to identify ALD (K70) and liver cirrhosis (K74) as of 2000.

We used the following CLD indicators: CLD mortality rates for 1981 to 1999 ; liver cirrhosis and ALD mortality rates for 2000 to 2007; liver cancer incidence rates for 1986 to 2007; liver cancer mortality rates for 1981 to 2009; and hospitalization rates for short-term physical care for liver disease for 1990 to 2005 .

We adjusted the proportions of the various parameters studied and the incidence, mortality and short-term hospitalization rates for CLD on the basis of age and sex for the overall Quebec population in 2001 and 2006, and calculated 99\% confidence intervals (CIs) of the estimates.

\section{Results}

The proportion of the Quebec population aged 20 to 64 years old that was overweight showed a slight upward trend, from $44.7 \%$ (99\% CI: 43.2-46.2) in 2000/2001 to $47.9 \%$ (99\% CI: 46.3-49.3) in 2007/2008. The overall obesity figures for this population also increased over the same period, from $12.6 \%$ (99\% CI: $11.6-13.7$ ) to $15.8 \%$ (99\% CI: 14.6-17.0). Men aged 25 to 44 years showed a particularly marked increase in obesity, from $12.7 \%$ (99\% CI: 10.6-14.7) to $16.8 \%$ (99\% CI: 14.1-19.6) (Figure 1).

The overall proportion of the population aged 12 years and older that used alcohol occasionally or daily over the previous 12 months rose slightly, from $81.1 \%$ in $2000 /$ 2001 to $81.9 \%$ in $2007 / 2008$. However, the proportion that drank alcohol daily rose from $8.3 \%(99 \% \mathrm{CI}: 7.5-9.1)$ to $10.7 \%$ (99\% CI: $9.8-11.5$ ) over the same period. This increase was more pronounced in women, from $4.6 \%$ (99\% CI: $4.1-5.2$ ) to $7.3 \%$ (99\% CI: $6.3-8.3$ ). We observed similar upward trends in those who had 14 or more alcoholic drinks in a seven-day period between 2000 and 2005 . With some exceptions, this upward trend was seen in all the age groups, but particularly in men aged 20 to 24 years. Although their proportions were lower than those among their male counterparts, there were marked increases in those women aged 45 to 64,20 to 24 and 12 to 19 years who had 14 or more alcoholic drinks in a seven-day period (Figure 2).

For heavy alcohol use (i.e. five or more alcoholic drinks on one occasion 12 or more times per year), the upward trend was observed for both men and women and for nearly all ages, except for the 12to 19-year age group. However, the most marked increase was for young adult women (20-24 years). For men in this age group, the proportion rose from $41.2 \%$ (99\% CI: $33.7-48.7$ ) in 2000/2001 to $46.4 \%$ (99\% CI: $37.8-55.1$ ) in $2007 /$ 2008; for women, it rose from $17.1 \%$ (99\% CI: $11.9-22.3)$ to 30.1 (99\% CI: 22.9-37.4) over the same period.

From 1990 to 2009, Quebec's RND recorded 28476 cases of $\mathrm{HBV}$ and 33490 cases of $\mathrm{HCV}$ (Figure 3). Of the HBV infections, $14 \%(n=3986)$ were classified as acute and $71 \%$ ( $\mathrm{n}=3986)$ were classified as chronic; the remaining 15\% were unspecified (this proportion rose after 2003). The overall incidence rate of acute cases also decreased significantly, from 6.5 per 100000 population in 1992 to 0.4 per 100000 population in 2009; this reduction occurred simultaneously in both sexes and in most age groups, but especially so in the 10- to 19 - and the 20- to 39-year age groups (data not shown). The number of reported chronic cases also fell over the same period, from a maximum of 1434 in 1992 to 634 in 2009. The number of $\mathrm{HCV}$ infection cases rose significantly in the 1990 s, and then started to fall gradually.

We observed a decrease in overall CLD and liver cirrhosis mortality rates between 1981 and 1999, from 24.2 per 100000 population ( $99 \%$ CI: $21.5-27.3$ ) to 13.0 (99\% CI: 11.3-14.9) for men, and from 8.2 per 100000 population (99\% CI: 6.8-9.9) to 5.8 (99\% CI: 4.8-6.9) for women (Figure 4 ). The mortality rate due to liver cirrhosis remained practically stable from 2000 to 2007; it dropped from 4.7 per 100000 population in 2000 (99\% CI: 4.05.4) to 4.6 (99\% CI: 4.0-5.2) in 2007. Similarly, ALD mortality rates fell from 3.3 per 100000 (99\% CI: 2.8-3.9) to 3.1 (99\% CI: 2.6-3.6) for the same years (Figure 5).

However, an overall increase in liver cancer incidence rates did occur between 1986/1988 and 2004/2006, from 3.8 per 100000 population ( $99 \% \mathrm{CI}: 3.4-4.2$ ) to 6.7 (99\% CI: 6.7-7.1). This increase was seen for both sexes: for women, this rate

\footnotetext{
* International Classification of Diseases 9th Revision.

$\dagger$ International Classification of Diseases 10th Revision.
} 
FIGURE 1

Proportion of the population with BMI $\geq 30 \mathrm{~kg} / \mathrm{m}^{2}$, by age and sex, excluding pregnant women, Quebec, CCHS, $2000-2008$

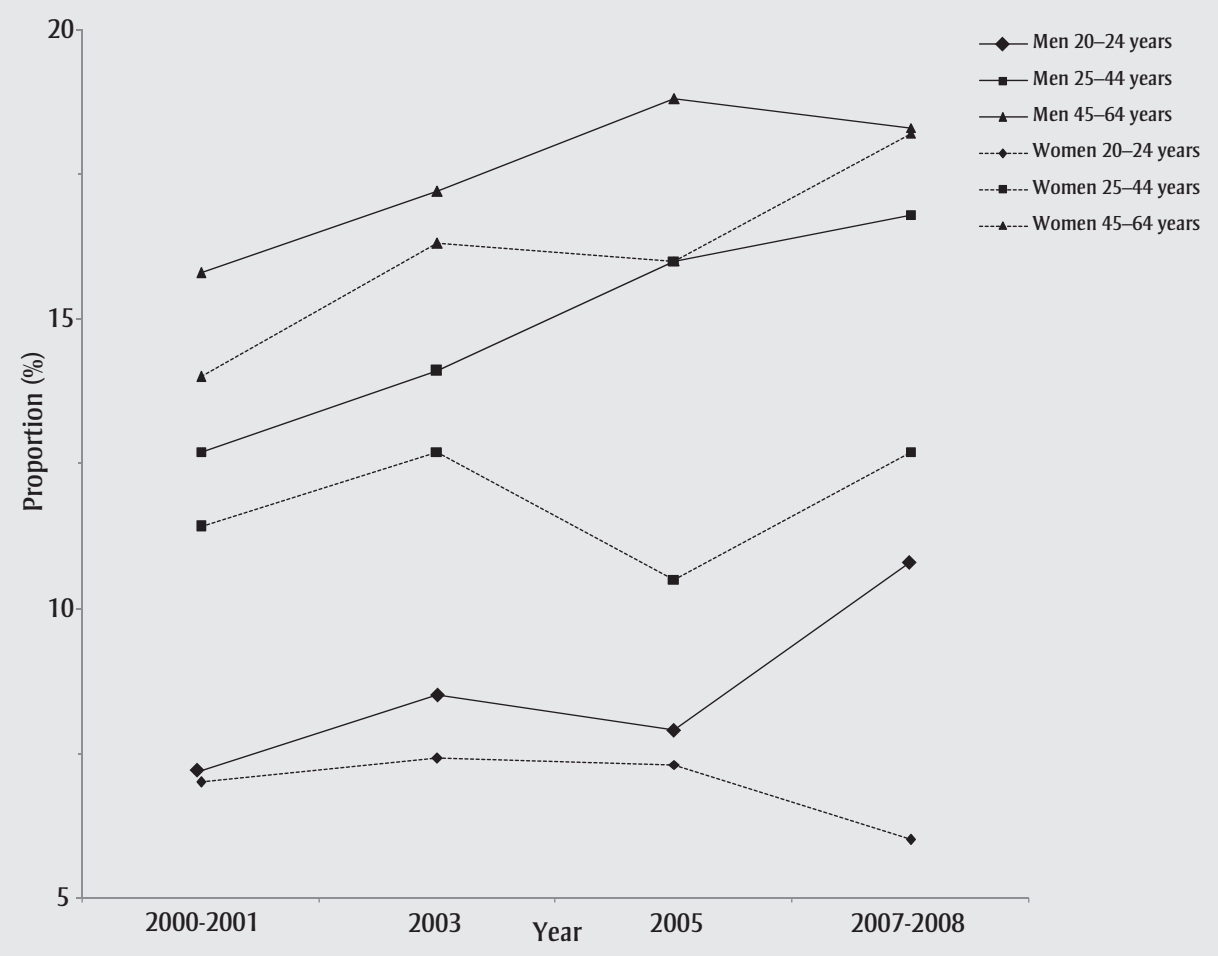

Abbreviations: BMI, body mass index; CCHS, Canadian Community Health Survey.

FIGURE 2

Proportion of the population, age $\geq 12$ years, that had $\geq 14$ alcoholic drinks over 7 consecutive days, by age and sex, Quebec, CCHS, 2000-2005

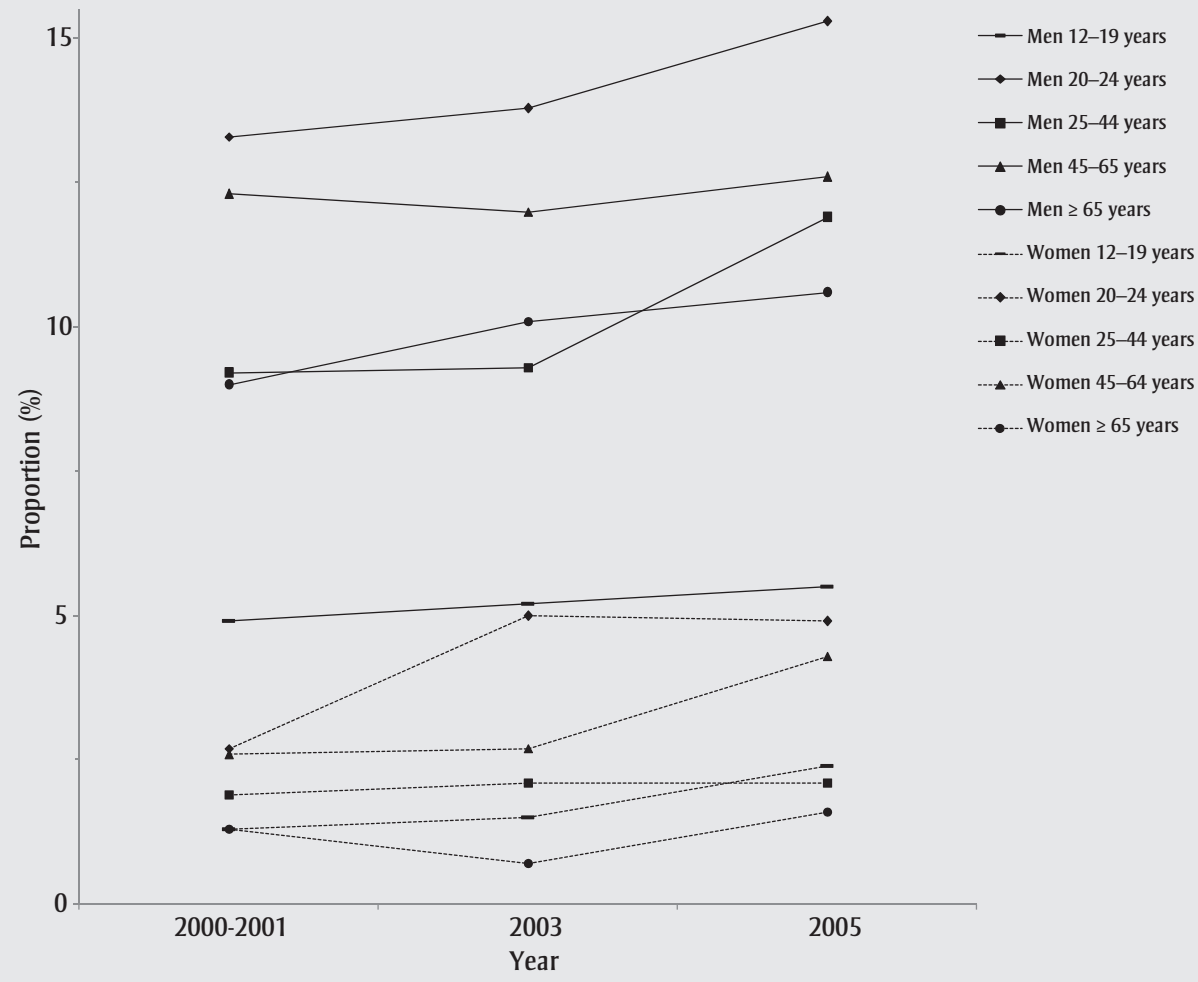

Abbreviation: CCHS, Canadian Community Health Survey. 
FIGURE 3

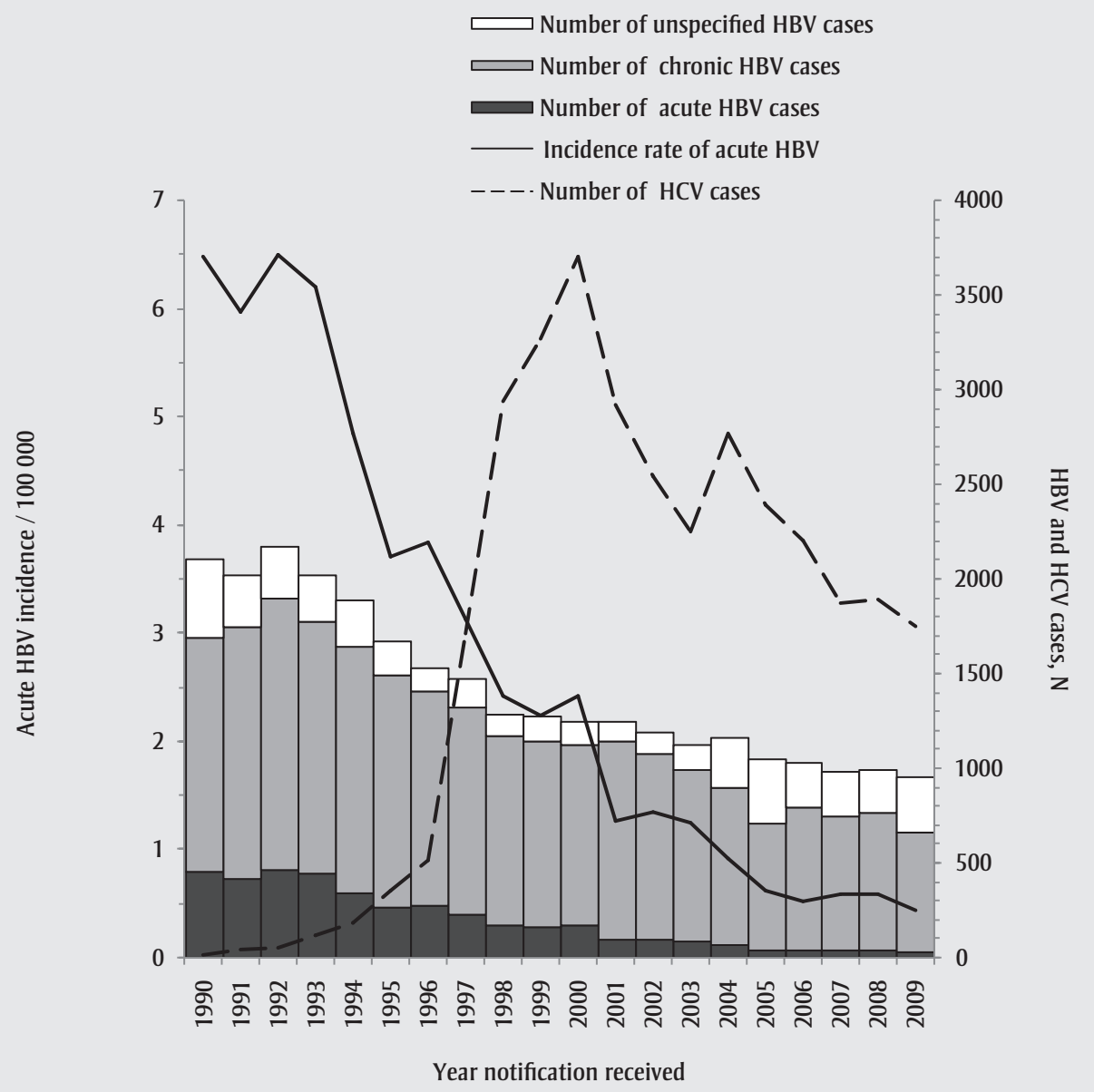

Abbreviations: HBV, viral hepatitis B; HCV, viral hepatitis C.

rose from 2.3 per 100000 population (99\% CI: $1.9-2.7)$ to 3.8 (99\% CI: $3.4-$ 4.3); for men, it rose from 5.7 per 100000 population (99\% CI: $5.0-6.8)$ to 10.2 (99\% CI: 9.4-11.0). The increase was significant in the 50- to 59-year age group and was largest among people aged 80 years and older; for them the rate rose from 19.6 per 100000 population (99\% CI: $14.5-26.5)$ to 41.1 (99\% CI: 35.6-47.5) (Figure 6).

Similarly, liver and intrahepatic bile duct cancer mortality rates in men showed the same upward trend, from 5.2 per 100000 population (99\% CI: 3.5-5.2) in 1981 to 8.5 (99\% CI: 7.4-9.9) in 2009 (provisional data) (Figure 7).

The short-term hospitalization rate due to CLDs fell from 1991 to 1997 and remained relatively stable in the years that followed (Figure 8).

\section{Discussion}

Based on our results, the upward trend in obesity in the Quebec population is alarming, especially among young men. These self-reported figures, drawn from various consecutive cycles of the CCHS, could be $4 \%$ to $8 \%$ less than directly measured values. ${ }^{24,25}$ Despite this limitation, the trend we observed is in line with the results of an ISQ-published ${ }^{25}$ study that based its results on direct measurements. This study reported that the prevalence of overweight and obesity among Quebecers aged 18 to 74 years rose from $43 \%$ in 1990 to $56 \%$ in $2004 .^{25}$

Obesity is a problem worldwide. In a recent study, Finucane et al. $^{26}$ estimating the BMI trends in 199 countries and territories among adults aged 20 years and older. They found the 2008 global prevalence of obesity to be $9.8 \%$ (95\% CI: 9.0-10.0) for men and $13.8 \%$ (95\% CI: 13.1-14.7) for women, nearly double the prevalence in 1980 (men: 4.8\%, 95\% CI: 4.0-5.7; women: $7.9 \%$, $95 \%$ CI: $6.8-$ 9.3). ${ }^{26}$ In a meta-analysis of 17 studies, Larsson and Wolk ${ }^{27}$ measured the association between weight and CLD risk. They reported a $17 \%$ increased risk of liver cancer for overweight and an 89\% increased risk for obesity, compared with that for normal weight. The relative risk (RR) was significantly higher for obesity in men $(\mathrm{RR}=2.42$; $95 \% \mathrm{CI}: 1.83-3.20)$ than in women $(\mathrm{RR}=1.67$; $95 \% \mathrm{CI}$ : $1.37-$ 2.03). ${ }^{27}$ Further studies will be necessary to add to the body of knowledge on obesity as a risk factor for other CLDs, such as non-alcoholic fatty liver. ${ }^{4,28,29}$

Alcohol is a known cause of cirrhosis, which predisposes a person to $\mathrm{HCC}^{30}$ 
FIGURE 4

Chronic liver disease and liver cirrhosis mortality rates, by sex, Quebec, 1981-1999

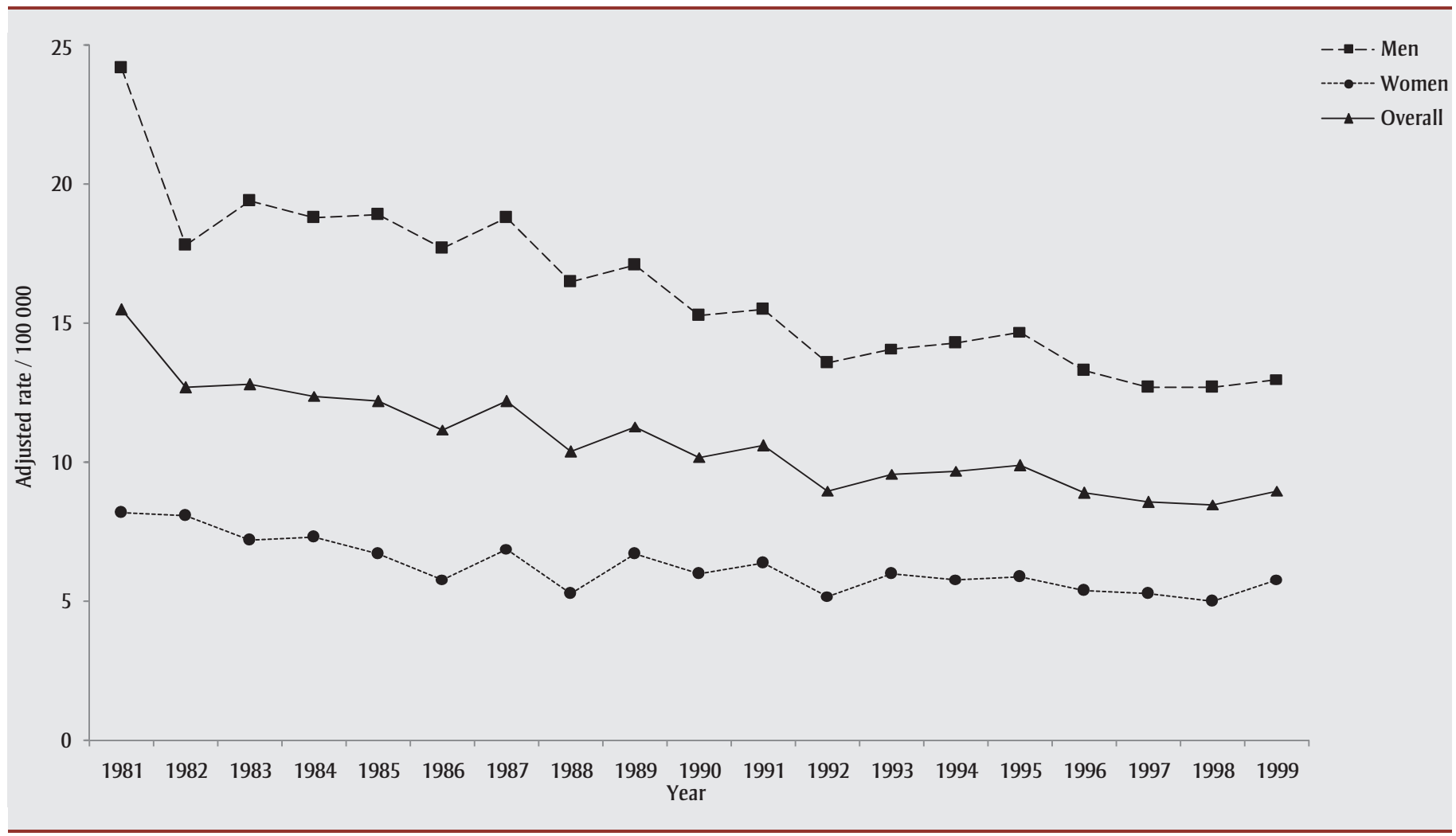

According to a 2010 report, alcohol sales have been on the rise in Quebec since the late $1990 \mathrm{~s}^{31}$ During the period of our study, the total proportion of people who drank alcohol remained the same, but the distribution in terms of frequency and heavy consumption increased. These trends are notable among young people and women. Other authors have reported similar findings. ${ }^{32}$
Chronic HBV and HCV infections are known causes of cirrhosis and HCC, and are linked to between $80 \%$ and $90 \%$ of HCC cases worldwide. ${ }^{33}$ Canada is considered a low-endemicity country for these

FIGURE 5

Alcoholic liver disease and hepatic fibrosis and cirrhosis mortality rates, by sex, Quebec, 2000-2007

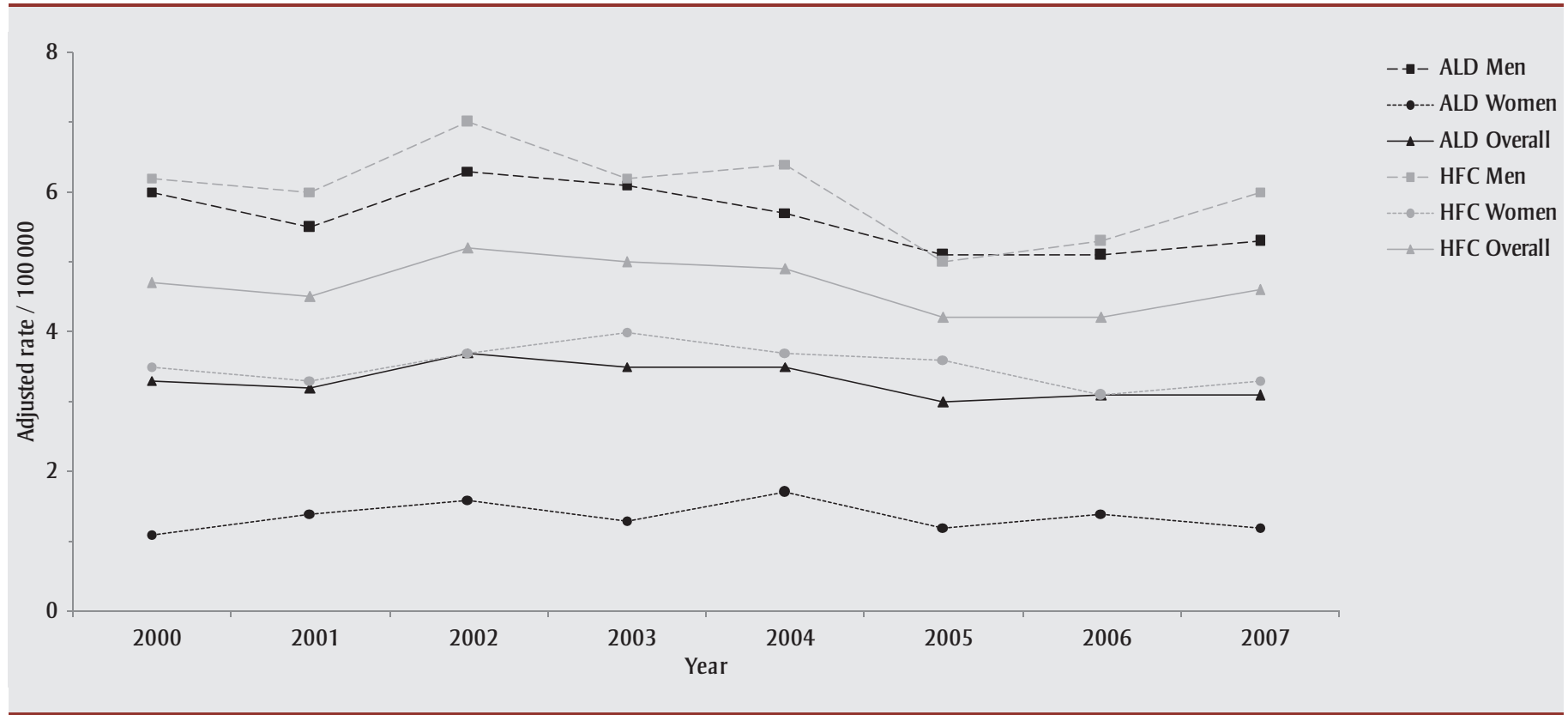

Abbreviations: ALD, alcoholic liver disease; HFC, hepatic fibrosis and cirrhosis. 
FIGURE 6

Liver cancer incidence rates per three-year period, by age, Quebec, 1986-2006

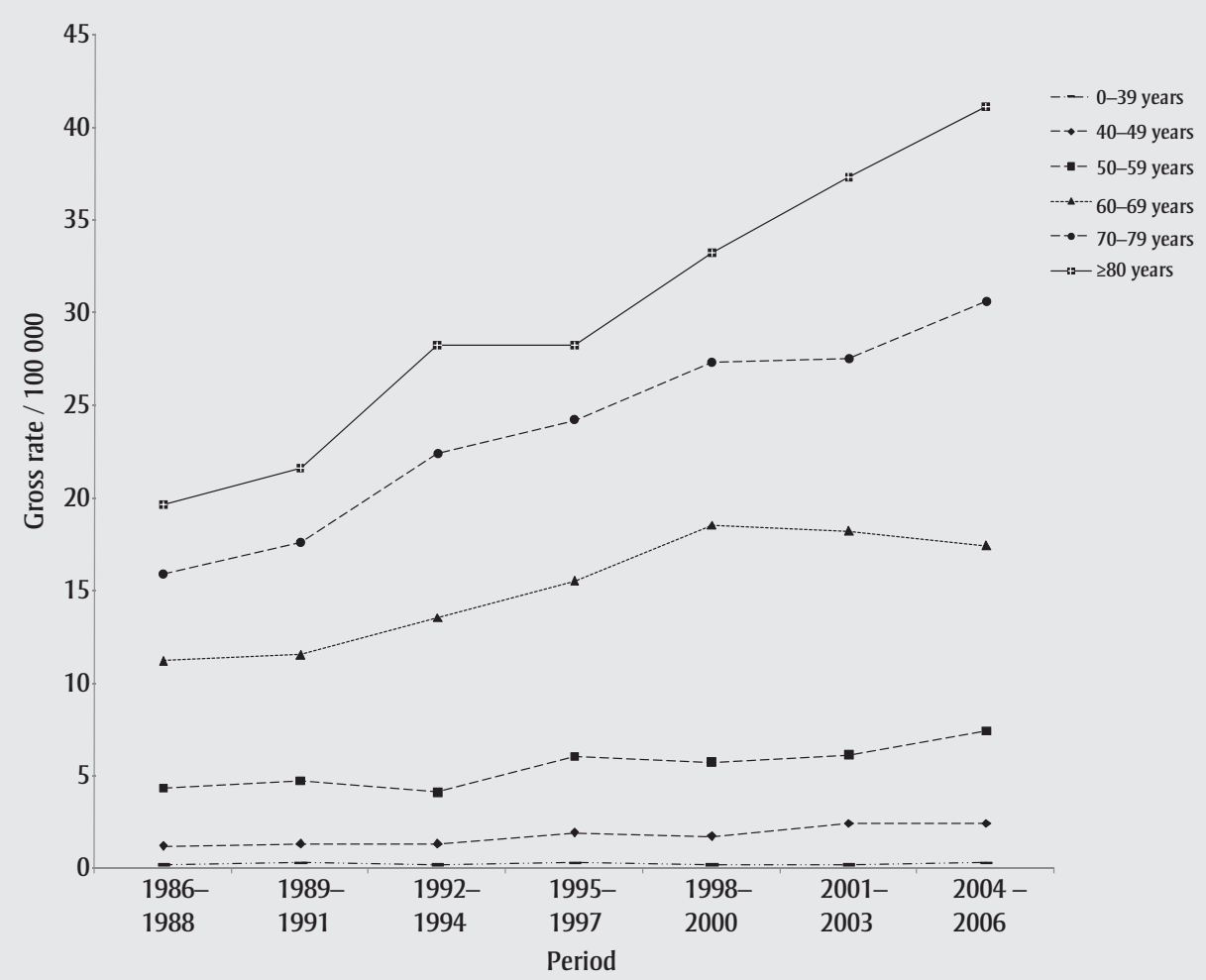

two infections. According to PHAC, $0.7 \%$ to $0.9 \%$ of the Canadian population has a chronic HBV infection. The HBV reporting rate fell considerably, from 11 per 100000 population ( $95 \%$ CI: $6.0-18.1$ ) to 3.3 (95\% CI: 1.6-4.8) between 1990 and 2007. A similar trend was observed in Quebec, with a marked decrease in incidence rate of acute HBV cases, likely as a result of expanded HBV immunization, including the school vaccination program introduced in $1994 .^{34}$

The numbers on reported HCV cases should be interpreted with caution. A large part of the observed increase in the number of cases reported in the 1990s is probably due to improvements in $\mathrm{HCV}$ detection and increased screening of populations at high risk of infection. The subsequent decrease in the 2000s could be as a result of duplicate episodes being removed from the RND, which was intensified in 2004 and applied retrospectively and prospectively. The decrease would also be due to prevention activities that target at-risk groups, including injec-

FIGURE 7

Liver cancer and intrahepatic bile duct cancer mortality rates, by sex, Quebec, 1981-2009

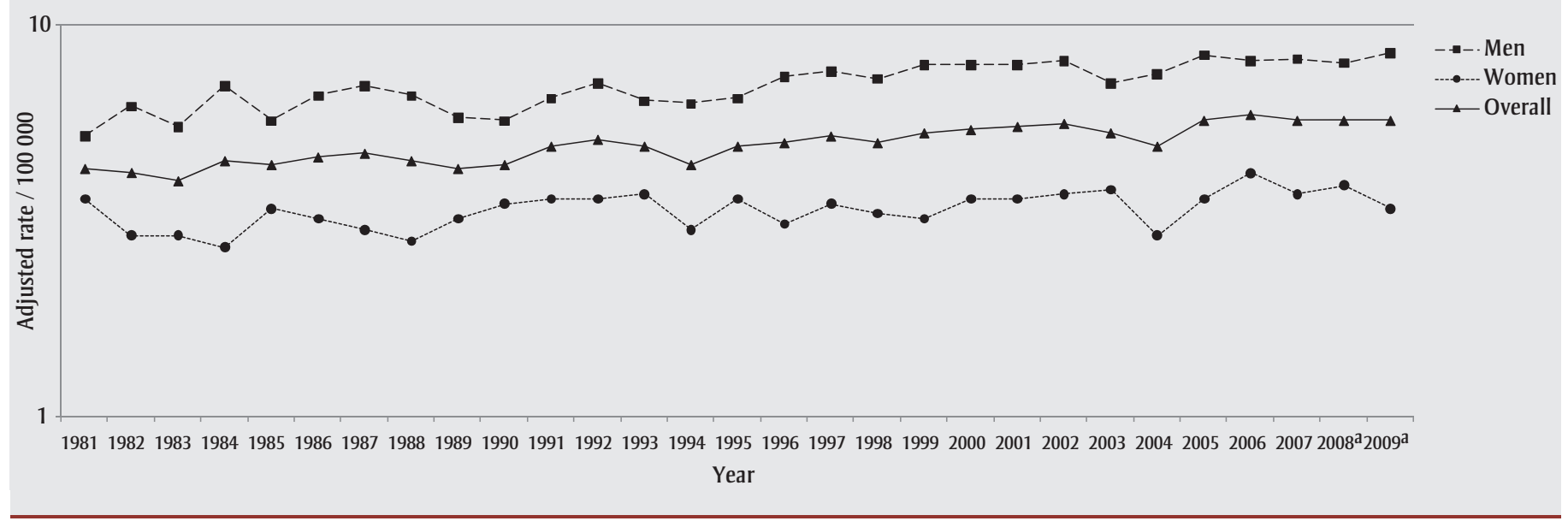

${ }^{\text {ap Provisional data. }}$ 
FIGURE 8

Hospitalization rates for short-term physical care for liver diseases, by sex, Quebec, 1990-2005

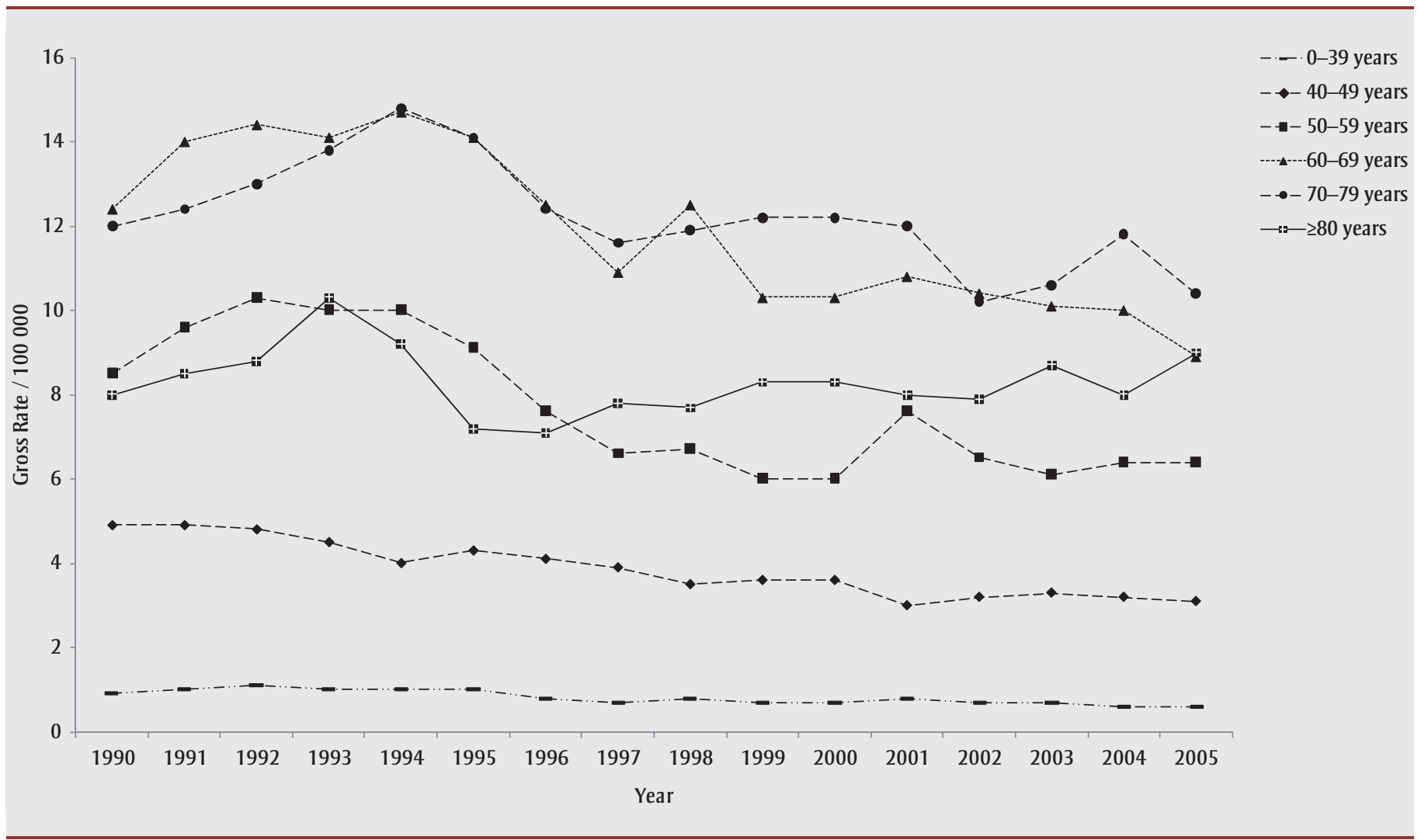

tion drug users. The 2003-2012 public health program for Quebec included among its goals the reduction in $\mathrm{HBV}$ and $\mathrm{HCV}$ incidence. ${ }^{35}$ Considering that between $75 \%$ and $85 \%$ of HCV infections become chronic, $5 \%$ to $20 \%$ of chronic infections lead to liver cirrhosis, and $1 \%$ to $5 \%$ of the people with $\mathrm{HCV}$ will die as a result of HCV-related cirrhosis or HCC, ${ }^{36}$ it is clear that comprehensive care measures for CLD patients are relevant and timely. Our results show that CLD and cirrhosis mortality rates fell by $42 \%$ between 1981 and 1999. These data are similar to those in Italy, Spain and Portugal, which report reductions of $25 \%$ to $30 \%$ since the 1970 s. These contrast with the cirrhosis mortality rates for England and Scotland, which are between $35 \%$ and $112 \%$, possibly because of the less restrictive policies on alcohol use in these countries. ${ }^{9}$ The decreased rates that we observed may be linked to better patient management and to more restrictive policies on sale of and access to alcohol in Canada. After 2000, mortality rates due to liver cirrhosis and ALD fluctuated, more or less reflecting the downward trend shown elsewhere.
Several studies have reported a recent increase in HCC incidence, ${ }^{2,32,37-41}$ and the situation in Quebec is no exception. Between 1998 and 2007, the liver cancer incidence rate in Quebec was 3.7 per 100 000 population ( $95 \%$ CI: $3.5-3.8$ ), ranking second after British Columbia (3.9; $95 \%$ CI: 3.7-4.1) among provinces/territories in Canada (data available on request). ${ }^{37}$ Our results show that this increase began after 1989/1991 and is particularly large for those aged 50 years and older. The liver cancer mortality rate reflects the incidence rate, emphasizing the highly lethal character of this kind of tumour. 2,32,37-41 The upward trends for liver cancer incidence and mortality in Quebec are similar to those observed in the rest of Canada. According to the Canadian Cancer Society, ${ }^{42}$ between 1997 and 2006 there was a statistically significant change in liver cancer incidence and mortality rates among men $3.1 \%$ and $2.2 \%$ a year, respectively; such a change is considered statistically significant at $2 \%$ or more a year). This increase reflects those reported in the United States, United Kingdom and most European coun- tries. ${ }^{9,39,43}$ The increase in the liver cancer incidence rate among older people could be linked to a cohort effect, and better management of these patients would probably improve their survival. The observed decrease in the liver cirrhosis mortality rate could be the result of therapeutic advances (e.g. more accessible and effective $\mathrm{HBV}$ and $\mathrm{HCV}$ antiviral treatments and liver transplants) and could eventually affect the HCC trends.

The decrease in the hospitalization rate for short-term physical care for liver diseases in Quebec in the late 1990s could be linked to the shift toward outpatient care, instituted as a cost-cutting measure, among other reasons. ${ }^{44}$

Despite having results comparable with those of other studies, our study has limitations that should be considered when interpreting the results. It is not possible to determine the distribution of the various CLD risk factors based on our results. The level of access granted for consulting the data sources did not allow for a more detailed breakdown of the 
episodes or conditions of interest. The CCHS data have significant limitations for intra- and intercycle comparability, owing to changes in methodology, despite the existence of guidelines for indicator comparability and interpretation. ${ }^{35,45,46}$ Since our observational study is limited to describing trends, a number of aspects related to measuring association and significant differences between the periods and populations studied were not explored. We favoured an overview of the CLD problems studied, drawing links between the determinants and disease states. We believe that this approach, while simple, is nevertheless relevant: it allows for formulation of hypotheses that can be validated in future studies and for highlighting the most important aspects of disease control for decision making.

\section{Acknowledgements}

We thank the Institut national de santé publique du Québec and the University Hospital of Bellvitge for their support for the internship that made it possible to complete this study.

There is no conflict of interest or funding source connected with the material presented in this article.

\section{References}

1. Bell BP, Manos MM, Zaman A, Terrault N, Thomas A, Navarro VJ, et al. The epidemiology of newly diagnosed chronic liver disease in gastroenterology practices in the United States: results from populationbased surveillance. Am J Gastroenterol. 2008;103(11):2727-36.

2. Sanyal AJ, Yoon SK, Lencioni R. The etiology of hepatocellular carcinoma and consequences for treatment. Oncologist. 2010;15 Suppl 4:14-22.

3. Severi T, van Malenstein $H$, Verslype $C$, van Pelt JF. Tumor initiation and progression in hepatocellular carcinoma: risk factors, classification, and therapeutic targets. Acta Pharmacol Sin. 2010;31(11):1409-20.

4. Marchesini G, Moscatiello S, Di Domizio S, Forlani G. Obesity-associated liver disease. J Clin Endocrinol Metab. 2008;93(11 Suppl 1): S74-80.
5. Corrao G, Bagnardi V, Zambon A, La Vecchia C. A meta-analysis of alcohol consumption and the risk of 15 diseases. Prev Med. 2004;38(5):613-9.

6. Tanaka K, Tsuji I, Tamakoshi A, Matsuo K, Ito $\mathrm{H}$, Wakai $\mathrm{K}$, et al. Obesity and liver cancer risk: an evaluation based on a systematic review of epidemiologic evidence among the Japanese population. Jpn J Clin Oncol. 2012;42(3):212-21.

7. Fattovich G, Stroffolini T, Zagni I, Donato F. Hepatocellular carcinoma in cirrhosis: incidence and risk factors. Gastroenterology. 2004;127(5 Suppl 1):S35-50.

8. Berzigotti A, Garcia-Tsao G, Bosch J, Grace ND, Burroughs AK, Morillas $\mathrm{R}$, et al. Obesity is an independent risk factor for clinical decompensation in patients with cirrhosis. Hepatology. 2011;54(2):555-61.

9. Leon DA, McCambridge J. Liver cirrhosis mortality rates in Britain, 1950 to 2002. Lancet. 2006;367(9511):645.

10. Murphy SL. Deaths: final data for 1998 . Natl Vital Stat Rep. 2000 Jul 24;48(11):1-105.

11. Anderson RN, Smith BL. Deaths: leading causes for 2002. Natl Vital Stat Rep. 2005;53(17):1-89.

12. Kung HC, Hoyert DL, Xu J, Murphy SL. Deaths: final data for 2005. Natl Vital Stat Rep. 2008;56(10):1-120.

13. Murphy SL, Xu JQ, Kochanek KD. Deaths: preliminary data for 2010. Natl Vital Stat Rep. 2012;60(4):1-52.

14. Mortality, summary list of causes 2008 . Frequency: annual. Ottawa (ON): Statistics Canada; 2011. [Statistics Canada, Catalogue No.: 84F0209X].

15. Lim SG, Mohammed R, Yuen MF, Kao JH. Prevention of hepatocellular carcinoma in hepatitis B virus infection. J Gastroenterol Hepatol. 2009;24(8):1352-7.

16. Asia-Pacific Working Party on Prevention of Hepatocellular Carcinoma. Prevention of hepatocellular carcinoma in the AsiaPacific region: consensus statements. J Gastroenterol Hepatol. 2010;25(4):657-63.
17. Portail de l'infocentre [Internet]. Québec (QC): Government of Quebec; 2010 [cited 2012 May 24]. Available at: www.infocentre .inspq.rtss.qc.ca

18. Canadian Community Health Survey (CCHS), Cycle 2.1 (2003). User Guide for the Public Use Microdata File. Ottawa (ON): Statistics Canada; 2005.

19. Surveillances des maladies à déclaration obligatoire au Québec. Définitions nosologiques. Maladies d'origine infectieuse. 8th edition [Internet]. Québec (QC): MSSS; 2011 [cited 2012 May 24]. Available from: http://publications.msss.gouv.qc.ca/acrobat /f/documentation/2011/11-268-01.pdf

20. Public Health Agency of Canada. Case definitions for communicable diseases under national surveillance. Canada Communicable Disease Report. 2009;35(S2):1-128.

21. Service du développement de l'information. La population du Québec par territoire des centres locaux de services communautaires, par territoire des réseaux locaux de services et par région sociosanitaire, de 1981 à 2031 [Internet]. Québec (QC): MSSS; 2010. Available from: http://publications .msss.gouv.qc.ca/acrobat/f/documentation /2010/10-407-01.pdf

22. Christiansen T, Bruus M, Lauritsen JM, Kreiner S. EpiData Analysis. V2.2.1.171. Data management and statistical analysis package [software]. Odense (DK): EpiData Association; 2009. Available from: http: //www.epidata.dk

23. Canadian Community Health Survey (CCHS) Cycle 3.1 (2005). Public Use Microdata File (PUMF). User Guide [Internet]. Ottawa (ON): Statistics Canada. 2006.

24. Institut national de santé publique du Québec and Ministère de la Santé et des Services sociaux du Québec, in collaboration with the Institut de la statistique du Québec. Portrait de santé du Québec et de ses régions 2006: deuxième rapport national sur l'état de santé de la population du Québec. Les analyses [Internet]. Québec (QC): INSPQ; 2006 [cited 2012 May 24]. Available from: http://www.inspq.qc.ca/pdf /publications/546-PortraitSante2006_Analyses .pdf 
25. Audet N. L'évolution de l'excès de poids chez les adultes québécois de 1990 à 2004: mesures directes. Zoom Santé [Internet]. Québec (QC): Institut de la statistique du Québec; 2007 [cited 2012 May 24]. Available from: www.stat.gouv.qc.ca/publications/sante /pdf2007/zoom_sante_juin07.pdf

26. Finucane MM, Stevens GA, Cowan MJ, Danaei G, Lin JK, Paciorek CJ, et al. National, regional, and global trends in body-mass index since 1980: systematic analysis of health examination surveys and epidemiological studies with 960 countryyears and 9.1 million participants. Lancet. 2011;377(9765):557-67.

27. Larsson SC, Wolk A. Overweight, obesity and risk of liver cancer: a meta-analysis of cohort studies. Br J Cancer. 2007;97(7):1005-8.

28. Bellentani S, Scaglioni F, Marino M, Bedogni G. Epidemiology of non-alcoholic fatty liver disease. Dig Dis. 2010;28(1):155-61.

29. Scheen AJ, Luyckx FH. Obesity and liver disease. Best Pract Res Clin Endocrinol Metab. 2002;16(4):703-16.

30. Food, nutrition, physical activity, and the prevention of cancer: a global perspective [Internet]. Washington (DC): World Cancer Research Fund; 2007 [cited 2011 May 24]. Joint publication of the American Institute for Cancer Research. Available from: http: //www.dietandcancerreport.org/cancer _resource_center/downloads/Second_Expert _Report_full.pdf

31. April N, Begin C, Morin R. La consommation d'alcool et la santé publique au Québec [Internet]. Québec (QC): INSPQ; 2010 [cited 2012 May 24]. Available from: http://www.inspq.qc.ca

32. Nordenstedt H, White DL, El-Serag HB. The changing pattern of epidemiology in hepatocellular carcinoma. Dig Liver Dis. 2010;42 Suppl 3:S206-S214.

33. Hepatitis B infection in Canada. Ottawa (ON): Public Health Agency of Canada; 2008.

34. Gilca V, Duval B, Boulianne N, Dion R, De Serres G. Impact of the Quebec schoolbased hepatitis B immunization program and potential benefit of the addition of an infant immunization program. Pediatr Infect Dis J. 2006;25(4):372-4.
35. Cardinal L, Francoeur D, Hamel M, Kirouac S, Theberge Y; Ministère de la Santé et des Services sociaux. Québec Public Health Program 2003-2012 [Internet]. Québec (QC): MSSS; 2003 [cited 2012 May 24]. Available from: http://publications.msss .gouv.qc.ca/acrobat/f/documentation/2003 103-216-02A.pdf

36. World Health Organization. Hepatitis C [Internet]. 2002 [cited 2012 May 24]. Available from: http://www.who.int/csr /disease/hepatitis/Hepc.pdf

37. Cancer Surveillance On-Line. Ottawa (ON): PHAC; 2007.

38. Ferlay J, Shin HR, Bray F, Forman D, Mathers C, Parkin DM. Estimates of worldwide burden of cancer in 2008: GLOBOCAN 2008. Int J Cancer. 2010;127(12):2893-917.

39. Jemal A, Siegel R, Xu J, Ward E. Cancer statistics, 2010. CA Cancer J Clin. 2010;60(5):277-300.

40. Marcos-Gragera R, Cardo X, Galceran J, Ribes J, Izquierdo A, Borras J. [Cancer incidence in Catalonia, 1998-2002]. Med Clin (Barc ). 2008;131 Suppl 1:4-10.

41. Michielsen PP, Francque SM, van Dongen JL. Viral hepatitis and hepatocellular carcinoma. World J Surg Oncol. 2005;3:27.

42. Canadian Cancer Society's Steering Committee: Canadian cancer statistics 2010. Toronto (ON): Canadian Cancer Society; 2010.

43. Ribes J, Pareja L, Esteban L, Clèries R. [Analysis of cancer incidence, survival and mortality according to the main tumoral localizations, 1985-2019: liver cancer]. Med Clin (Barc). 2008;131 Suppl 1:83-7.

44. L'Association des praticiens de service social en milieu de santé du Québec. Le virage ambulatoire et le service social en milieu de santé. Réflexions et propositions [Internet]. Service social. 1996 [cited 2013 Feb 11]:45(3);175-91. Available from: http://www.erudit.org/revue/ss/1996/v45 /n3/706744ar.pdf
45. Institut de la statistique du Québec. Plan commun de surveillance de l'état de santé de la population et de ses déterminants: Guide spécifique des aspects méthodologiques des données d'enquêtes sociosanitaires du Plan commun de surveillance - Enquête sur la santé dans les collectivités canadiennes, cycles 1.1, 2.1, 3.1 et 2007-2008 [Internet]. Québec (QC): INSPQ; 2011 May [cited 2012 May 24]. In collaboration with Institut national de santé publique du Québec and Ministère de la Santé et des Services sociaux du Québec. Available from: http://www.stat.gouv .qc.ca/publications/sante/doc_technique /ESCC_guide_methodologique_mai2011.pdf

46. Plante N, Côté L, Courtemanche R, Nanhou $\mathrm{V}$. Incidence des changements méthodologiques de l'Enquête sur la santé dans les collectivités canadiennes sur la comparabilité entre les cycles 1.12 .1 et 3.1 aux niveaux provincial et régional de même que sur la comparabilité régionale intra cycle [Internet]. Québec (QC): Institut de la statistique du Québec; 2010 Feb [cited 2012 May 24]. Available from: http://www.stat.gouv.qc .ca/publications/sante/doc_technique/ESCC _comparabilite_cycles_11_21_21.pdf 